Current Perspectives on Medicinal and Aromatic Plants

An International Journal ISSN: 2619-9645 | e-ISSN: 2667-5722

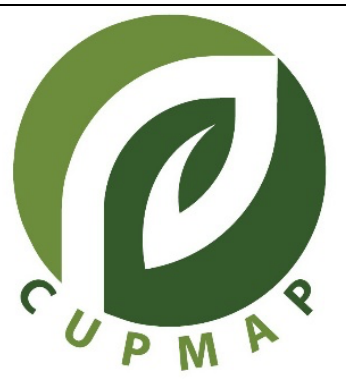

\title{
Can Medicinal Plants Help in the Treatment of the New Coronavirus? Some R \& D Aspects in Slovak Republic
}

\author{
Ivan SALAMON \\ Department of Ecology, Faculty of Humanities and Natural Sciences, \\ University of Presov, 01, 17th November St., SK-080 01 Presov, Slovakia. \\ *Corresponding author: ivan.salamon@unipo.sk
}

\begin{abstract}
At the end of February 2020, the World Health Organization published the final report: Report of the WHOChina Joint Mission on Coronavirus Disease 2019 (COVID-19), which directly presents the findings of a joint mission of experts from around the world in China in the period after the pandemic. Researchers have been searching for anything that could help other countries fight the new type of 2019-nCoV virus; among other things, how to prevent it's spread or how to treat it as effectively as possible. In China, doctors, pharmacists and ordinary citizens use the phytotherapy of traditional Chinese medicine on a daily basis to prevent and treat COVID-19. As part of this report, it is recommended to carry out research on natural substances isolated from medicinal plants, the aim of which should be to evaluate their real effectiveness against this disease. Experts agree that we are using vaccines or medicament that would be effective in the fight against the new type of coronavirus SARS CoV-2. While we look forward to it, let us remember which medicinal plants and their natural substances can bring us relief from its manifestations during COVID-19 disease. It is important to know, that relevant herbal drugs and supplements standardized to the active antiviral natural substance. They can play an important role in the treatment and management of the coronavirus pandemic and its subsequent recurrences.
\end{abstract}

Key Words: COVID-19 pandemic, herbs, immune effect, natural components

(c) CUPMAP. All rights reserved.

\section{Introduction}

All over the world medicinal plants fulfill their role at the intersection between the traditional medicine and modern medicine, which uses mainly synthetic drugs. The success of traditional Chinese medicine in the treatment of civilization diseases lies in its overlap with conventional methods of treatment used by general practitioners. One of the latest examples of the significant contribution of traditional Chinese phytotherapy is the use of the artemisinin from wormwood (Artemisia annua L.) in treating the malaria. In 2015, the Nobel Prize in Physiology and Medicine was attributed to Chinese scientist Dr. Youyou $\mathrm{Tu}$ for her contribution to artemisinin discovery (Karkalik et al., 2018). The pandemic of coronavirus disease 2019 (COVID-19) is changing the world like never before. This crisis is unlikely contained in the absence of effective therapeutics or vaccine. It is the duty of every researcher and his institution to 
contribute to solving this unfavorable global situation. The purpose of the paper is to present some aspects of the use of medicinal plants with antiviral activities and supporting research conducted in Slovakia at the University of Presov in Presov.

\section{Introduction}

All over the world medicinal plants fulfill their role at the intersection between the traditional medicine and modern medicine, which uses mainly synthetic drugs. The success of traditional Chinese medicine in the treatment of civilization diseases lies in its overlap with conventional methods of treatment used by general practitioners. One of the latest examples of the significant contribution of traditional Chinese phytotherapy is the use of the artemisinin from wormwood (Artemisia annua L.) in treating the malaria. In 2015, the Nobel Prize in Physiology and Medicine was attributed to Chinese scientist Dr. Youyou $\mathrm{Tu}$ for her contribution to artemisinin discovery (Karkalik et al., 2018). The pandemic of coronavirus disease 2019 (COVID-19) is changing the world like never before. This crisis is unlikely contained in the absence of effective therapeutics or vaccine. It is the duty of every researcher and his institution to contribute to solving this unfavorable global situation. The purpose of the paper is to present some aspects of the use of medicinal plants with antiviral activities and supporting research conducted in Slovakia at the University of Presov in Presov.

\section{World differences in the use of medicinal plants}

In Europe, the use of medicinal plants is relatively widespread, but their therapeutic effect is not significantly and sufficiently appreciated. On the contrary, conventional medicine dominates in the United States, and is completely separate from the traditional medicine and herbal medicine. U.S. general practitioners use and prescribe only synthetic drugs and the population is being vaccinated.

It is true that the course of the spread of coronavirus 2019-nCoV in individual parts of the world (China - Europe - USA - South America) depends on the discipline of the population in the implementation of all measures to slow down the virus spread. However, somewhere in the background is the knowledge and use of medicinal plants and isolated natural substances that act and treat COVID-19 comprehensively without any side effect. The number of people who were infected, cured or who died of the disease on various continents of the world clearly indicate that medicinal plants and their secondary metabolites (natural substances) can play a role in managing of the infection (Benarda and Pandiella, 2020).

\section{University of Presov and $R \& D$ in Slovakia}

For more than 15 years at the University of Presov, we have been producing drugs (dry plant parts) of medicinal plants with high contents of therapeutically active natural substances for plant-derived products of several collaborating pharmaceutical companies at home and abroad. Massproduced medicinal products require special attention in connection with its definition, specification, testing and proof of quality, which we have mastered. A thorough evaluation is mandatory not only for medicinal products originating from individual plant species, but for each herbal 
product and also for marketed products such as food (teas), food supplements and cosmetics.

The knowledge of the main active constituents, their identification, the knowledge of the chemical composition (chemical profile/fingerprint) and determination of the biological activity is required when using medicinal plants. Quantitative contents of individual natural substances determine the value of the plant, also in terms of its commercial use.

A significant success at the international level and unique in the Slovak Republic is the use of bred varieties of medicinal plants with a high content of therapeutically active substances, either their own (legally protected throughout the EU) or introduced into cultivation from neighboring countries (Salamon et al., 2018). Within the identification of natural substances and their qualitative and quantitative composition, we have introduced a number of spectrophotometric methods and chromatographic methods with methodology for each plant species separately.

As part of international cooperation with several institutions, for example: Institute of Microbiology and Virology of Zobolotny, UAV, Kiev, Ukraine and Institute of Epidemiology and Infection Diseases of L.V. Gromashevsky, NAMN, Kiev, Ukraine, we also focus on testing the antiviral activity of isolated plant extracts, essential oils and natural components.

\section{Coronavirus SARS CoV-2}

The new strain of 2019-nCoV virus belongs to droplet infections of the respiratory tract and lungs (Andersen et al., 2020), the estimated incubation time of the disease is 2 to 14 days, but it can be longer. Symptoms of COVID 19 include fever above $38^{\circ} \mathrm{C}$, cough, difficulty breathing, muscle and headache, tiredness and malaise. However, some individuals may transmit the virus without feeling the symptoms of the disease. The replication cycle of the virus (also 2019-nCoV) in the host cell (respiratory system) has its sequence (Helmy-Yosra et al., 2020): - early phase of infection: recognition, attachment, penetration; - introduction into the cell: stripping, release of the genome into the nucleus; - late phase: genome replication, macromolecules, fusion and release; eclipse phase (period from genome stripping): loss of infectivity after fusion and emergence of new virions; and - latent period - the period of eclipse until the release of a number of virions and their attack on a significant number of host cells (Coutarda et al., 2020).

\section{Inhibition of hemagglutinin protein and viral neuraminidase enzyme}

The hemagglutinin protein, together with the enzyme neuramidase, helps the virus to multiply in the host cell. Several scientific experiments (Wilks et al., 2012; ZakayRones et al., 1995) have shown that natural components (anthocyanin flavonoids) extracted from the fruits of the elderberry (Sambucus nigra L.) prevent the spread of swine flu infection by preventing its entry into the $\mathrm{H}_{1} \mathrm{~N}_{1}$ virus from entering the lung host cell. The effects of these substances are comparable to the chemical structure of Oseltamivir ${ }^{\circledR}$ (trade name: Tamiflu, manufactured by Roche, Basel, Switzerland). In vitro experiments have shown that these flavonoids are able to prevent the entry of various parasitic 
strains of influenza viruses into human cells (Ishiguro et al., 2018).

The very interesting news with the use of elderberry extracts came from the US, where experienced the second-strongest growth in the mainstream channel in 2019, and sales surged in the first half of 2020 due to the COVID-19 pandemic. This is the second consecutive year of mainstream sales growth of more than $100 \%$ for this herb, which is commonly used for immune support and cold and flu symptoms (Smith et al., 2019). A meta-analysis of elderberry for cold- and flu-related respiratory symptoms published in February 2019, for example, found that the herb "substantially reduce upper respiratory symptoms." The authors of the analysis concluded that elderberry supplementation could help reduce "antibiotic misuse for upper respiratory symptoms due to viral infections, and [could be] a potentially safer alternative to prescription drugs for routine cases of the common cold and influenza (Hawkins et al., 2019).

\section{Substances that prevent the virus from progressing}

Another natural substance that prevents the virus from entering the cell is rosmarinic acid. It can be extracted from several species of medicinal plants, such as balm (Melissa officinalis L.), sage (Salvia officinalis L.), thyme (Thymus vulgaris L.), origanum (Origanum vulgare L.) and peppermint (Mentha $\times$ piperita L.). However, the problem with this plant is the large variability of the content of the natural substance (from 8.5 to $28.5 \mathrm{mg} . \mathrm{kg}$ 1), which depends not only on the chemotype, but mainly on the soil and climatic conditions for cultivation. Rosmarinic acid is a naturally occurring polyphenolic compound. The qualitative and quantitative compositions of the main aromatic and polyphenolic constituents were examined and compared in lemon balm leaves from two years cultivation. The results show total hydroxycinnamic compounds $6.2 \pm 0.5 \%$, contents of rosmarinic acid $1.4 \pm 0.1 \%$ (in 2010) and $1.7 \pm 0.1 \%$ (in 2014) and total flavonoid compounds $0.5 \%$ (Friedman, 2015). In our research, we focused on the extraction of balm leaves of a new variety of 'Citronella' and the determination of rosemarinic acid quantity. High contents of this natural substance have been confirmed. It is possibly to recommend the use of this balm variety for the production of high quality raw material for the pharmaceutical industry (Salamon et al., 2019).

The enzyme neuraminidase is located on the surface of the virus and allows it to exit the host cells. This enzyme is blocked by other natural substances, including flavonoid anthocyanin (cyanidine-3sambubiocide, identified amount: 8200 ng. $\mathrm{ml}^{-1}$ ) isolated from the elderberry fruits (Sambucus nigra L.) (Wu et al., 2015; Swaminathan et al., 2013). The drug product with antiviral effect may be lyophilisate of anthocyanins, isolated from elderberry fruits using freeze-drying (lyophilization). Anthocyanins are instable in different conditions and our process of freeze-drying stabilizes them. Lyophilization is used in cases where it is necessary to remove water or occasionally other components from solutions (anthocyanins) sensitive to temperature, $\mathrm{pH}$, light or change in structure, usually of biological origin without changing the original properties and their long-term stabilization. The qualitative and quantitative characteristics of these 
flavonoids were determined by LCMS IT TOF (Salamon et al., 2021). The final product of anthocyanins in our R\&D could be used as food supplement, gelatin tablets, but also injections. They have been suggested to be beneficial for cardiovascular and neurodegenerative disease, as well as eye, muscle disorders and sarcopenia, even for possible dietary treatment of Duchenne muscular dystrophy (Wicks et al., 2018).

\section{Defense ability of the organism (immunity)}

In their viral infection, human cells are prevented from producing interferons into tissues and blood. These are special proteins (called IFN- $\beta$ ) that serve as information about their involvement and a signal to trigger the defense mechanisms, i.e. the formation of cells killing the intruder (immune response). At that moment, an inflammatory process takes place in the body, which in our case is accompanied by fever. It is not clear how raising the body temperature helps to suppress the infection. On the one hand, it can help increase the activity of defense mechanisms, for example by making antibodies. Sometimes, however, there is a situation, where the body responds incorrectly to its own cells and considers them foreign. He defends itself. Then we are talking about the auto immune diseases. In the case of COVID-19, severe pneumonia, and as a result of its complications, death can occur. It is therefore necessary to eliminate the body's high temperature by all possible means. Anthocyanin flavonoids extracted from the fruits of elderberry (Sambucus nigra L.) have, in addition to suppressing the replication of the virus in the host cell, also the ability to increase the production of interferons (IFN- $\beta$ ). In this context, there has already been a discussion as to whether the use of a standardized extract of these natural substances can elicit an auto-immune response and thus human death. The claim that these phenomena are unrelated is based primarily on a long history of using basal extracts to support immunity (Frokiaer et al., 2021; Barak et al., 2001).

It refers to Sambucol ${ }^{\circledR}$ (manufactured by Pharma Care Inc., San Diego, CA, USA), which has a special and unique extraction process and has undergone more than 20 years of scientific research and is currently distributed in 50 countries around the world (Chrubasik et al., 2015; Knudsen et al., 2015). Another example of the healing power of natural substances is Echinacea angustifolia DC. It is well known for its immunostimulatory substances (echinacoside, echinacin, rutoside, isobutylamides and others), which have the ability to increase the production of interferons (IFN- $\beta$ ) (Wu et al., 2009). Their antiviral activity is comparable to the already mentioned preparation of Oseltamivir ${ }^{\circledR}$. For the treatment of viral infections in children, Echinacin $₫$ (producer: MEDA Pharma GmbH \& Co. KG, Radebeul, Germany) is recommended, for which the species Echinacea purpurea (L.) MOENCH is used. It has been shown that such a method of treatment can significantly shorten the duration of infection compared to other methods of treatment (Rauš et al., 2015).

Further scientific research points to the ability of mass-produced preparations from species of the genus Echinacea to strengthen and stabilize the immune system in diseases of viral respiratory 
origin. Echinacea (Echinacea spp.) sales increased by $4.9 \%$ from 2018, making it the second top-selling ingredient, and ivy leaf (Hedera helix L.) sales increased by $14 \%$, making it the sixth top-selling supplement in this channel (Smith et al., 2020).

\section{PLpro inhibitory effects}

The papain-like protease (PLpro) of severe acute respiratory syndrome SARS-CoV-2 plays essential roles in virus replication and immune evasion (Gaoa et al., 2021). PLpro is an attractive target because it plays an essential role in cleavage and maturation of viral polyproteins, assembly of the replicase-transcriptase complex, and disruption of host responses. It was determined collection of structures details inhibitors recognition and interactions providing fundamental molecular and mechanistic insight into PLpro. All compounds inhibit the peptidase activity of PLpro in vitro, some block SARS-CoV-2 replication in cell culture assays. These findings will accelerate structure-based drug design efforts targeting PLpro to identify high-affinity inhibitors of clinical value (Osipiuk et al., 2021).

Several natural compounds were found to possess promising PLpro inhibitory effects. Indeed, Song et al. (2014) demonstrated that six cinnamic amides extracted from Tribulus terrestris $\mathrm{L}$. fruits were able to inhibit SARS-CoV PLpro. Terrestrimine showed the best inhibitory activity of SARS-CoV PLpro. The first contribution from Slovakia presents the information about an occurrence of this plant species and quantity determination of the specific constituents and heavy metal pollution in this plant material. The expeditions for general collection were organized several times a year (1999 - 2001) in chosen localities of Western Slovakia / Nesvady, Nove Zamky / and a small area cultivation was carried out in Nitra and Streda nad Bodrogom (Eastern Slovakia). The quantity of furostanol saponins is various in different plant parts and was modified by growing conditions (Salamon et al., 2006). The high interest on the production of puncture vine (Tribulus terrestris L.) for different purposes led scientists in Slovakia to start its cultivation, but climatic conditions greatly influence the cultivation of the plant. The Slovakian study aimed to the introduction of puncture vine into large cultivation scale was carried out. Two different methods of cultivation were compared and production of biomass and evaluation of the content of furostanol saponins were done. Transplantation of seedlings raised in the greenhouse into the open field was more effective for the production of high amount of biomass and active components than using plants that are directly sown. The transplantation of seedlings into open field is suitable for the puncture vine cultivation as it increases biomass production (Salamon et al., 2016).

\section{Help with the fever}

Fever (febris, pyrexia) is a common pathological symptom in acute inflammatory diseases of the respiratory system. Fever is not a disease, but a nonspecific symptom of a possible disease. In addition to bed rest and a rich supply of fluids, fever-reducing drugs (antipyretic action) containing natural substances and sweating agents (diaphoretic effect) can prove effective. For this purpose chamomile (Matricaria recutita L.) is very well suited, because of a high content of sesquiterpenes -/-/- $\alpha$-bisabolol and chamazulene in essential oil, or the application of dry extracts standardized to 
a high content of apigenins (Salamon, 2019), which have an effect on several physiological functions of the human body and has anti-inflammatory, antioxidant, antibacterial and antiviral activities.

\section{Conclusion: Herbs - good remedies in the treatment of viral diseases}

Return to natural healing substances is basically not a return, because many of them are used every day in medicines. However, in the light of events, it is even more important today (than ever before) to explore the unexplored possibilities of medicinal plants and to maximally support the search for ways to their therapeutically active substances in all available ways.

\section{Acknowledgements}

R \& D were supported by the Ministry of Education, Science, Research and Sport of the Slovak Republic, the project: 001620001 (MS SR-3634/2010-11) "Isolation of Natural Plant Substances by Lyophilisation and Change of their QualitativeQuantitative Properties".

\section{Conflicts of Interest}

The author declares that the research was conducted in the absence of any commercial or financial relationships that could be construed as a potential conflict of interest.

\section{Author Contribution Statements}

Ivan salamon designed and wrote the paper.

\section{References}

1. Andersen, K.G., Rambaut, A., Lipkin, W.I., Holmes, E.C., Garry, R.F. 2020. The Proximal Origin of SARS-CoV-2. Nature medicine, 26 (4), 450-452.
2. Barak V, Halperin T, Kalickman I. 2001. The effect of Sambucol, a Black Elderberry-based, Natural Product, on the Production of Human Cytokines: I. inflammatory cytokines. European Cytokine Network. 12(2), 290-296

3. Benarda, B., Pandiella, A. 2020. Medicinal Plants as Sources of Active Molecules against COVID-19 (Review). Frontiers in Pharmacology. 11(1189), 1-16

4. Chrubasik, S. 2015. Review of Pharmacological Effects and Clinical Efficacy of Fruit Products and Functional Foods from Elderberry (Sambucus spp.) as Compared with Chokeberry (Aronia melanocarpa L.). Acta Horticulturae. 1061, 8992

5. Coutarda, B., Valle, C., De Lamballerie, X., Canard, B., Seidahc, N.G., Decroly, E. 2020. The Spike Glycoprotein of the New Coronavirus 2019-nCoV Contains a Furin-like Cleavage Site Absent in $\mathrm{CoV}$ of the Same Clade. Antiviral research. 176(2), 104-112.

6. Friedman, T. 2015. The Effect of Rosmarinic Acid on Immunological and Neurological Systems: A Basic Science and Clinical Review. Journal of Restorative Medicine. 4(1), 50-59

7. Frokiaer, H., Henningsen, L., Metzdorff, S.B., Weiss, G., Roller, M., Flanagan, J. 2012. Astragalus Root and Elderberry Fruit Extracts Enhance the IFN-beta Stimulatory Effects of Lactobacillus acidophilus in Murine-derived Dendritic Cells. PLoS One. 7(10), 478-482

8. Gaoa, X., Qina, B., Chena, P., Zhua, K., Houa, P., Wojdylab, J.A., Wang, M., Cuia, S. 2021. Crystal Structure of SARS-CoV-2 Papain-like Protease. Acta Pharmaceutica Sinica B, 11(4), 237-245

9. Hawkins, J,, Baker, C., Cherry, L., Dunne, E. 2019. Black Elderberry (Sambucus nigra) Supplementation Effectively Treats upper Respiratory Symptoms: a Meta-analysis of Randomized, Controlled Clinical Trials. Complementary Therapies in Medicine. 42(6), 361-365.

10. Helmy, Y.A., Fawzy, M., Elaswad, A., Sobieh, A., Kenney, S.P., Shehata, A.A. 2020. The COVID-19 Pandemic: A Comprehensive Review of Taxonomy, Genetics, Epidemiology, Diagnosis, Treatment, and Control. Journal of Clinical Medicine 9(4), 1225

11. Ishiguro, N., Koseki, N., Kaiho, M. et al. 2018. Clinical Effectiveness of Four Neuraminidase Inhibitors (Oseltamivir, Zanamivir, Laninamivir, and Peramivir) for Children with Influenza A and $B$ in the 2014-2015 to 2016-2017 Influenza Seasons in Japan. Journal of Infection Chemotheraphy. 24(6), 449-457

12. Karkalík, Š., Rudá-Kučerová, J. 2018. Malária, jej liečba a profylaxia (in Slovak). Klinická farmakologia a farmácia. 32(2), 20-27

13. Knudsen, B.F., Kaack, K.V. 2015. Review of Human Health and Disease Claims for Elderberry 
(Sambucus nigra) Fruit. Acta Horticulturae. (1061), 121-131

14.Osipiuk, J., Azizi, S.A., Dvorkin, S., Endres, M., Jedrzejczak, R., Jones, K. A., Kang, S., Kathayat, R.S., Youngchang, K., Lisnyak, V.G., Maki, S.L., Nicolaescu, V., Taylor, C.A., Tesar, C., Zhang, Y.A., Zhou, Z., Randall, G., Michalska, K., Snyder, S.A., Bryan C. Dickinson, B.C., Joachimiak, A. 2021. Structure of Papain-like Protease from SARS-CoV-2 and its Complexes with Noncovalent Inhibitors. Nature Communications. 12(1), 1-17

15. Rauš, K., Klein, P., Schoop, R., Fisher, P. 2015. Effect of an Echinacea-based Hot Drink Versus Oseltamivir in Influenza Treatment: a Randomized, Double-blind, Double-dummy, Multicenter, Noninferiority. Current Therapeutic Research - Clinical and Experimental. 77(2), 6672

16.Salamon, I., Sezer, E.N.S., Kryvtsova, M., Labun, P. 2021. Antiproliferative and Antimicrobial Activity of Anthocyanins from Berry Fruits after their Isolation and Freeze-Drying. Applied Sciences - MDPI, (11):1-15

17.Salamon, I., Kryvtsova, M.V., Trush, K.I., Fandalyuk, A.I., Spivak, M.J. 2019. Agroecological Cultivation, Secondary Metabolite Characteristics and Microbiological Tests of Lemon Balm (Melissa officinalis L.) - the Variety Citronella. Regulatory Mechanisms in Biosystems, 10(3), 265-269

18.Salamon, I. 2019. Slovak Chamomile Varieties and their Comparison of Natural Components. Current Perspective on Medicinal and Aromatic Plants (CUPMAP). 2(2), 59-65

19.Salamon, I., Haban, M., Otepka, P., Habanova, M. 2018. Perspectives of Small- and LargeCultivation of Medicinal, Aromatic and Spice Plants in Slovakia. Medicinal Plants International Journal of Phytomedicines and Related Industries, 9(4), 261-267

20.Salamon, I., Grulova, D., DeFeo, V. 2016. Comparison of Two Methods for Field Grow of Puncture Vine (Tribulus terrestris L.) in Slovakia. Acta Agriculturae Scandinavica, Section B - Soil \& Plant Science. 66(3), 267-271

21.Salamon, I., Haban, M., Baranec, T., Habanova, M., Knoll, M. 2006. The Occurrence of Puncture Vine (Tribulus terrestris L.) and its Metabolic
Characteristics in Slovakia. Biologia, 61(1), 2530

22.Smith, T., May, G., Eckl, V., Reynolds, C.M. 2020. US Sales of Herbal Supplements Increase by 8.6 $\%$ in 2019. Herbalgram, 127(1), 54-67

23.Song, Y.H., Kim, D.W., Curtis-Long, M.J., Yuk, H.J., Wang, Y., Zhuang, N., Lee, K.H, Jeon, K.S., Park, K.H. 2014. Papain-like protease (PLpro) inhibitory effects of cinnamic amides from Tribulus terrestris fruits. Biological and Pharmaceutical, 37(6), 1021-1028

24.Swaminathan, K, Dyason, J, Maggioni, A., von Itzstein, M., Kevin, M. Downard, K.M. 2013. Binding of a Natural Anthocyanin Inhibitor to Influenza Neuraminidase by Mass Spectrometry. Analytical and Bioanalytical Chemistry. (405), 6563-6572

25. Wicks, S.M., Salamon, I., Calderon, A.I., de Blanco, E.J.C., Mahady, G.B., 2018. Sarcopenia, Diabetes, and Nutritional Intervention. In Nutritional and Therapeutic Interventions for Diabetes and Metabolic Syndrome; Elsevier Science Publishing Co. Inc.: San Diego, United States, 279-292, ISBN 978-0-12-812019-4.

26.Wilks, S, de Graaf, M., Smith, D.J., Burke, D.F. 2012. A Review of Influenza Hemagglutinin Receptor Binding as it Relates to Pandemic Properties. Vaccine. 30(29), 4369-4376

27.Wu, H., Johnson, M.C., Lu, C.H., Fritsche, A.L., Thomas, Z.C., Greenlief, C.M. 2015. Determination of Anthocyanins and Total Polyphenols in a Variety of Elderberry Juices by UPLC-MS/MS and other Methods. Acta Horticulturae, 1061. 43-51

28. Wu, H., Nardone, A., Lacetera, N. 2009. Effects of a Standardized Purified Dry Extract from Echinacea angustifolia on Proliferation and Interferon Gamma Secretion of Peripheral Blood Mononuclear Cells in Dairy Heifers. Research in Veterinary Science. 87(3), 396-398

29.Zakay-Rones, Z., Varsano, N., Zlotnik, M., Manor, O., Regev, L., Schlesinger, M., Mumcuoglu, M. 1995. Inhibition of Several Strains of Influenza Virus in vitro and Reduction of Symptoms by an Elderberry Extract (Sambucus nigra L.) during an Outbreak of Influenza B Panama. Journal of Alternative Complementary Medicine. 1(4), 36136 